CAHIERS DE

NARRATOLOGIE

\section{Cahiers de Narratologie}

Analyse et théorie narratives

38 | 2020

Lusor in Fabula. Jeu vidéo et nouvelles frontières du récit

\title{
Jean-Yves Boursier : D'Auxerre à Mauthausen et Prague. Le voyage de Robert Simon dans le « siècle 》)
}

Jean-Paul Aubert

\section{OpenEdition}

\section{Journals}

Electronic version

URL: http://journals.openedition.org/narratologie/11587

DOI: 10.4000/narratologie. 11587

ISSN: 1765-307X

\section{Publisher}

LIRCES

\section{Electronic reference}

Jean-Paul Aubert, "Jean-Yves Boursier : D'Auxerre à Mauthausen et Praque. Le voyage de Robert Simon dans le "siècle »", Cahiers de Narratologie [Online], 38 | 2020, Online since 11 January 2021, connection on 29 January 2021. URL: http://journals.openedition.org/narratologie/11587 ; DOI: https://doi.org/10.4000/narratologie. 11587

This text was automatically generated on 29 January 2021

Article L.111-1 du Code de la propriété intellectuelle. 


\title{
Jean-Yves Boursier : D’Auxerre à Mauthausen et Prague. Le voyage de Robert Simon dans le « siècle »
}

\author{
Jean-Paul Aubert
}

\section{REFERENCES}

Vulaines-sur-Seine, Éditions du Croquant, 2020, collection Sociologie historique

Dans la continuité de son précédent ouvrage consacré à Armand Simonnot ${ }^{1}$, ancien bûcheron du Morvan, militant pacifiste, Franc-Tireur et Partisan (FTP), devenu dans l'après-guerre le garde du corps de Charles Tillon, Jean-Yves Boursier nous livre le nouveau récit d'une vie singulière.

Robert Simon, instituteur dans l'Yonne, s'engage tout d'abord dans les rangs socialistes de la SFIO avant de rejoindre le PSOP pivertiste. Pacifiste, responsable des Comités antifascistes de son département dans les années trente, déserteur en septembre 1939, il participe brièvement au Mouvement National Révolutionnaire, un regroupement éphémère de trotskistes et d'anciens socialistes, puis au réseau gaulliste "Dastard ", avant d'adhérer au PCF en janvier 1942 et de participer à la résistance armée au sein du "Détachement Valmy ». Il est arrêté par la police de Vichy en octobre 1942, torturé, puis livré aux Allemands. Déporté à Mauthausen du 23 mars 1943 jusqu'au 6 mai 1945, il joue un rôle actif dans le camp au sein de la résistance communiste. Dans l'après-guerre il devient un permanent du Parti, chargé du journal Le Travailleur de l'Yonne. Mais, se sentant rapidement à l'étroit dans le carcan provincial, Robert Simon prend le large. De 1949 à 1953, c'est entre Paris et Prague qu'il déploie son énergie, au service de la revue du Conseil Mondial de la Paix. A partir de 1959 et jusqu'à son exclusion en 1970, Robert Simon participe à l'opposition interne au sein du PCF avec le groupe «Unir ». Tout au long de l'après-guerre, ses engagements successifs vont de pair avec son implication 
constante dans la défense des droits des déportés au sein de la FNDIRP et de l'Amicale de Mauthausen.

3 L'ouvrage retrace ainsi l'itinéraire politique d'un homme de courage et de conviction, impliqué dans les grands combats de son siècle. C'est toute une vie qui défile, comme une épopée intellectuelle et militante à travers l'Europe. D'Auxerre à Paris, de Mauthausen à Prague, de la Gauche Révolutionnaire pivertiste au groupe "Unir », la trajectoire peut sembler sinueuse mais elle est en réalité balisée par la fidélité au socialisme originel du père et par la détestation de la guerre et des notables.

Aux origines du courant de la micro-histoire dans lequel s'inscrit l'ouvrage, les interrogations sur le rôle de l'individu dans une histoire nécessairement collective, prennent ici une ampleur tout à fait particulière. Car, si la vie de Robert Simon atteste une éthique personnelle et un courage hors du commun, elle est mue avant tout par une conscience sociale et politique chevillée au corps. Ce sont les organisations politiques auxquelles il adhère successivement qui dessinent les horizons de son engagement personnel et ce sont les élans collectifs qui donnent sens à sa destinée individuelle. Ce n'est donc pas un hasard si Robert Simon rejette la brève période de sa vie au cours de laquelle il dit avoir cessé toute activité politique et syndicale et où, ainsi qu'il l'écrit lui-même dans son roman inachevé, il se voit rejeté "dans une espèce d'isolement désespéré dont il risquait de ne plus sortir ». Longuement analysés dans le livre, ces mois qui précèdent la guerre sont celle de l'impasse du pacifisme dans laquelle échouent socialistes et psopistes. Elles sont vécues par Robert Simon comme une impasse personnelle. L'acte individuel de désertion qui conclut cette sombre période apparaît comme l'aboutissement d'une déroute collective et précède le retour à l'action qui, pour Simon, vaut finalement mieux que le verbe.

5 Résultat d'une enquête longue et minutieuse, l'ouvrage parvient, par la confrontation des témoignages, des récits et des documents d'archives, à éclairer d'un jour nouveau les enjeux politiques du "court vingtième siècle». Il décrit les errances des gauches françaises confrontées à la question de la guerre et démonte les mécanismes politiques qui ont conduit les partis staliniens à sacrifier des générations de militants communistes compétents et généreux.

6 Le livre est aussi un plaidoyer pour une manière d'écrire l'Histoire, forgée par une conviction exprimée dès les premières pages : «Si le témoin n'a pas toujours raison, l'archive ne parle pas toute seule» (p. 33). Sans être dupe des déformations et des oublis qu'ils comportent nécessairement, l'enquête entend redonner leur légitimité aux témoignages individuels qu'il serait d'autant plus aisé de révoquer que les acteurs de l'époque concernée ont presque tous disparu. Ce n'est donc pas une Histoire univoque qui s'écrit, mais une myriade de récits produits par des subjectivités multiples qui s'entremêlent, se combinent et parfois se contredisent. Dénouer les écheveaux, écouter les témoins, confronter leurs propos, retourner aux documents d'archives, tel est le travail de l'historien anthropologue dont l'ambition est de comprendre comment avec ses dissonances et ses discordances, la polyphonie de récits individuels parfois labyrinthiques contribue à restaurer la complexité du réel. Le résultat est ce livre qui questionne et déconstruit les grandes fresques institutionnalisées avec leur part de mythifications et de falsifications et toutes les « histoires officielles » qu'elles émanent d'un état ou d'un parti. 


\section{NOTES}

1. Jean-Yves Boursier, Armand Simonnot, bûcheron du Morvan. Communisme, Résistance, Maquis, Paris, L'Harmattan, 2013, collection "Terrains: récits et fictions". Voir également Marc Marti, «Compte rendu : «Armand Simonnot, bûcheron du Morvan. Communisme, Résistance ", Cahiers de Narratologie [Online], 26 | 2014, Online since 11 September 2014, connection on 20 April 2019. URL : http://journals.openedition.org/narratologie/6841 ; DOI : 10.4000/ narratologie.6841

\section{AUTHORS}

\section{JEAN-PAUL AUBERT}

J.P. Aubert, UCA 